\title{
Nab-paclitaxel: potential for the treatment of advanced pancreatic cancer
}

This article was published in the following Dove Press journal:

OncoTargets and Therapy

4 February 2014

Number of times this article has been viewed

\author{
Marwan Al-Hajeili ${ }^{1,2}$ \\ Asfar S Azmi ${ }^{3}$ \\ Minsig $\mathrm{Choi}^{2}$
}

'Department of Medicine, King Abdulaziz University, Jeddah, Saudi Arabia; ' ${ }^{2}$ Department of Oncology, Karmanos Cancer Institute, Wayne State University, Detroit, MI, USA; ${ }^{3}$ Department of Pathology, Wayne State University, Detroit, MI, USA

Correspondence: Minsig Choi Department of Oncology, Wayne State University, Karmanos Cancer Institute, 4100 John R Detroit, MI, USA Email choim@karmanos.org

\begin{abstract}
Advanced pancreatic adenocarcinoma is a deadly disease and is considered incurable. For the past two decades, gemcitabine remained the major chemotherapeutic drug with modest clinical benefit. Many chemotherapy and targeted agents were combined with gemcitabine but failed to demonstrate improvement in pancreatic cancer (PC) survival. Taxanes (paclitaxel, docetaxel) were introduced in the clinic as anti-microtubule agents and showed activity against PC cells in vitro; however, clinical efficacy was limited. Nab-paclitaxel (Abraxane) is an albuminbound paclitaxel that has shown clinical activity in advanced breast and lung cancer. Recently, nab-paclitaxel was tested in a large Phase III clinical trial in combination with gemcitabine for the treatment of advanced PC. The data showed that the addition of nab-paclitaxel improved the response rate ( $7 \%$ in gemcitabine alone versus $23 \%$ in combination), progression-free survival (from 3.7 months to 5.5 months), and overall survival from 6.7 months to 8.5 months, compared to single agent gemcitabine. Through this review, we provide the preclinical and clinical progress in the development of nab-paclitaxel for the treatment of metastatic PC.
\end{abstract}

Keywords: pancreatic adenocarcinoma, nab-paclitaxel, abraxane, gemcitabine

\section{Introduction}

Pancreatic adenocarcinoma comprises 3\% of estimated new cancer cases each year, with 44,030 new cases and 37,660 deaths expected in 2013. It is the fourth most common cause of cancer mortality in the US. ${ }^{1}$ Pancreatic cancer (PC) continues to be one of the most aggressive malignancies with a 5 -year survival of less than $2 \%{ }^{2}$ Pancreatic adenocarcinoma can be defined in terms of accumulating genetic mutations in key tumor activator and inhibitor genes such as Kras and myriad of other regulatory molecules. ${ }^{3}$ Germline mutations in BRCA2, PALB2, CDKN2A, STK11, and PRSS1 genes, and Lynch syndrome, is associated with increased risk of PC. ${ }^{4,5}$ Progression of PC begins with the appearance of the abnormal expression of $\mathrm{Pdx} 1$, hedgehog signaling, Kras oncogenes, and aberration of tumor suppressor genes like p16, p53, and SMAD4/ DPC4. ${ }^{3-5}$ These pathways are fed-forward by frequently cited mutations and the aberrant expression of the DNA sequence; epigenetic factors have been implicated through molecular modifications and dysregulation of microRNAs (miRNAs).

For decades, few drugs have been effective in advanced PC. ${ }^{6}$ Gemcitabine was considered the only available option for this disease with a median survival of 5.4 months. ${ }^{7}$ Gemcitabine is a pro-drug that enters the cells aided by membrane transporters. ${ }^{8}$ Once inside, it is phosphorylated by deoxycytidine kinase (dCK) to an active form. ${ }^{9}$ Both gemcitabine diphosphate ( $\mathrm{dFdCTP}$ ) and gemcitabine triphosphate ( $\mathrm{dFdCTP})$ inhibit processes required for DNA synthesis. Nevertheless, a number of studies have shown that pancreatic cells 
become resistant to gemcitabine through various mechanisms. For example, Hong et al showed that a sub-population of cancer stem-like cells (CSLCs) was expanded during the acquisition of gemcitabine resistance in pancreatic tumors. After exposure to high-dose gemcitabine, CSLCs that are CD44-positive cells reproliferated and reconstituted the resistant cell population. Most importantly, these cells overexpress the multi-drug resistance markers and among the $\mathrm{ABC}$ transporters, the expression of ABCB1 (MDR1) was significantly augmented in these resistant CSLCs. ${ }^{10}$ Additionally, our group has recently demonstrated that PC cells acquire resistance to gemcitabine through enhanced plasticity or in other words, undergo epithelial-mesenchymal transition in their phenotype. ${ }^{8}$

Many chemotherapeutic agents in combination with gemcitabine and targeted therapies have failed to improve the low survival rate. Clinicians incorporated anti-EGFR (epidermal growth factor receptor) erlotinib in combination with gemcitabine where the combination improved survival by a mere 2 weeks and the doublet was granted US Food and Drug Administration (FDA) approval. ${ }^{11}$ Meanwhile, taxane and related compounds that have been recognized to be effective in treating breast and lung cancers were tried in advanced PC as well. Unfortunately, their toxicity parameters were not favorable and clinical efficacy was not promising. ${ }^{12}$ Recently, albumin-bound paclitaxel (Abraxane) has demonstrated superior efficacy in combination with gemcitabine, leading to its FDA approval. In this review, we will discuss clinical progress in the treatment of PC with a special focus on the recently approved nab-paclitaxel.

\section{Taxanes}

Taxane rings are isolated from bark of Yew (Taxus brevifolia and Taxus baccata), ${ }^{13}$ and has antimicrotubular activity and inhibits depolymerization. These mitotic-inhibiting agents exert cytotoxic effects against wide ranges of different tumors. ${ }^{14}$ Being pleiotropic agents from plant origin, they have poor aqueous solubility, and extraction requires synthetic solvents. For taxotere, polysorbate 80 is used and for paclitaxel, cremophor EL is used, which is composed of castor oil and ethanol. ${ }^{15}$ The presence of the cremophor was considered the primary reason for the allergic reaction associated with the administration of paclitaxel. ${ }^{16}$ Furthermore, the addition of cremophor limits the dose, bioavailability, and drug concentration in the tumor tissue. ${ }^{17}$

\section{Taxanes in PC}

Taxanes were studied in advanced PC as a single agent or in combination. Okada et al investigated docetaxel as a first-line therapy for 21 advanced PC chemo-naïve patients. They observed a median overall survival of 118 days (95\% confidence interval [CI]: 105-158 days) and no objective response was noted. ${ }^{18}$ The main grade 3-4 toxicities were myelosuppression along with anemia, thrombocytopenia, and nausea/ vomiting. Docetaxel, administered at $60 \mathrm{mg} / \mathrm{m}^{2}$, did not show significant anti-tumor activity in patients with metastatic PC. In another study, Androulakis et al demonstrated the efficacy of docetaxel as a first-line agent for 33 advanced PC patients (with performance status $0-1$ ), and found an overall survival of 36 weeks. ${ }^{19}$ In this case, docetaxel was administered at $100 \mathrm{mg} / \mathrm{m}^{2}$, along with granulocyte colony-stimulating factor on day 2 throughout day 10 every 3 weeks. Although docetaxel demonstrated a marginal objective activity, modest clinical benefit was noted. In a similar fashion, Rougier et al demonstrated the median overall survival to be 7 months in 40 patients with locally advanced and metastatic PC. ${ }^{20}$ The incidence and severity of adverse events were similar to other docetaxel studies.

The combination of docetaxel and gemcitabine was studied in chemo-naïve PC patients. Ryan et al demonstrated the efficacy of the combination (docetaxel administered at $60 \mathrm{mg} / \mathrm{m}^{2}$ and gemcitabine at $600 \mathrm{mg} / \mathrm{m}^{2}$ ) in 33 patients (performance status of $0-1$ ) and found a median overall survival of 8.9 months (95\% CI: 5.2-11.2 months). ${ }^{21}$ The objective response rate was $18 \%$, and the 1-year survival rate was $29 \%$. Stathopoulos et al investigated gemcitabine at $1,000 \mathrm{mg} / \mathrm{m}^{2}$ and docetaxel at $100 \mathrm{mg} / \mathrm{m}^{2}$ in 54 patients with metastatic PC and found the median survival to be 26 weeks. ${ }^{22}$ All these trials had a limited number of patients, with survival ranging from 4-8 months and clinical activity did not warrant further Phase III trials.

\section{Nab-paclitaxel}

Nab-paclitaxel is a colloidal suspension of $130 \mathrm{~nm}$ particles homogenized in human serum albumin bound to paclitaxel. Sparreboom et al demonstrated the pharmacokinetics of nab-paclitaxel and paclitaxel in humans and in animals models, and showed that the volumes of distribution were higher by $50 \%$ for nab-paclitaxel..$^{23}$ Better bioavailability of nab-paclitaxel compared to serum-bound paclitaxel was noted in other studies as well. ${ }^{24}$ Desai et al demonstrated in nude mice bearing human xenograft tumors, that intratumoral accumulation, absorption, binding to the endothelial cells, and transportation were higher for nab-paclitaxel compared with paclitaxel..$^{25,26}$

The drug delivery of nab-paclitaxel is associated with the gp60 albumin receptor as well as secreted protein acidic 
and rich in cysteine (SPARC) expressed in many cancer cells. ${ }^{27,28}$ SPARC has a high affinity to albumin; therefore, nab-paclitaxel has increased intratumoral concentration in cancer patients. ${ }^{29}$ SPARC is a calcium-binding protein, and is present on tumor cells and stromal fibroblasts, which play an important role in promoting epithelial-to-mesenchymal transition and invasion through matrix metalloprotease expression. Overexpression of SPARC in the stroma is recognized to promote cancer cell invasion and metastasis. ${ }^{30}$ Infante et al showed that PC patients had worse prognoses with higher SPARC on stromal fibroblast. ${ }^{31}$ Since SPARC is a mechanism for nab-paclitaxel delivery, pancreatic tumors with higher expressions of SPARC were associated with improved survival for patients who received the combination of nab-paclitaxel and gemcitabine in early clinical trials. ${ }^{32,33}$ Current studies are evaluating if SPARC could be used as a biomarker for nab-paclitaxel-based chemotherapy.

\section{Nab-paclitaxel and gemcitabine in PC}

Chemotherapy resistance to common agents like gemcitabine is one of the reasons why PC cells become more aggressive and cause poor outcomes in these patients. PC cells stroma serves as a mechanical barrier and promotes tumor formation, progression, invasion, and metastasis. ${ }^{34-36}$ Alvarez et al demonstrated cancer stroma and tumor softening, mainly related to nab-paclitaxel and not gemcitabine. ${ }^{37}$ Von Hoff et al examined the molecular profile of different solid tumors from 91 patients to identify potential targets and resistance to the current chemotherapeutic agents, including combining gemcitabine with different agents and possible synergism. ${ }^{38}$ Frese et al demonstrated how cytidine deaminase, an enzyme involved in the metabolic deactivation of gemcitabine, could be inhibited by nab-paclitaxel..$^{9}$ Preclinical data suggested that SPARC was overexpressed in pancreatic adenocarcinoma samples and the early work of Von Hoff ${ }^{38}$ used SPARC as a possible target for nab-paclitaxel. In the pilot Phase I/II study, a combination of nab-paclitaxel and gemcitabine was used in advanced PC patients. The results of the clinical efficacy data were promising. The median overall survival was 12.2 months (95\% CI: 8.9-17.9 months), the median progression-free survival was 7.9 months (95\% CI: 5.8-11.0 months), and the overall response rate was $46 \% .{ }^{32}$ In the study, a PET scan was used to assess if metabolic responders do better than nonresponders. The subset analysis showed that patients who had complete metabolic response had a median overall survival of 20.1 months versus 10.3 months in non-responders $(P=0.01){ }^{32}$ Zhang et al performed a similar study in 21 Chinese patients and had a median overall survival of 12.2 months (95\% CI: 9.5-14.8 months) and an overall response rate of $28 \%$ in advanced PC patients. ${ }^{39}$

These promising results of early clinical trials led to the largest Phase III trial in advanced PC.$^{40}$ It was a randomized study comparing gemcitabine and nab-paclitaxel to single agent gemcitabine in 861 untreated advanced PC patients. The study was conducted in 151 sites on three continents, including many in community practices in the US. The patients were distributed in a 1:1 ratio, with 431 in the combination arm and 430 in the standard gemcitabine arm. Patient demographics were well matched in both the experimental and control group as shown in Table 1 . The median age of the study population was 63 with slightly more male predominance. The study included patients with a Karnofsky performance status (KPS) of 70-100. Therefore, the study included some patients who had a SWOG (Southwest Oncology Group) performance status of 2 . The majority of patients had liver metastasis and up to $46 \%$ of patients had three or more sites of metastatic disease. Since the study required a normal bilirubin level, majority of patients had primary PC in the body and tail of the pancreas and about $43 \%$ had the primary location in the head of the pancreas. Biliary stents were reported in $19 \%$ of experimental and $16 \%$ of the standard arm, respectively.

$\mathrm{Nab}$-paclitaxel was given at $125 \mathrm{mg} / \mathrm{m}^{2}$ with gemcitabine at $1,000 \mathrm{mg} / \mathrm{m}^{2}$ on days 1,8 , and 15 , every 4 weeks. Gemcitabine was given weekly at $1,000 \mathrm{mg} / \mathrm{m}^{2}$ for 7 weeks followed by 1 week of rest on the first cycle. In the subsequent

Table I Demographic information and baseline characteristics of the MPACT study

\begin{tabular}{llll}
\hline Variables & $\begin{array}{l}\text { Nab-paclitaxel }+ \\
\text { gemcitabine } \\
\text { N=43 I }\end{array}$ & $\begin{array}{l}\text { Gemcitabine } \\
\mathbf{N}=\mathbf{4 3 0}\end{array}$ & $\begin{array}{l}\text { All patients } \\
\mathbf{N}=\mathbf{8 6} \text { I }\end{array}$ \\
\hline $\begin{array}{lll}\text { Age } \\
\text { Median years }\end{array}$ & $62(27-68)$ & $63(32-88)$ & $63(27-88)$ \\
$\geq 65$ years old $\%$ & $41 \%$ & $44 \%$ & $42 \%$ \\
Sex & & & \\
$\quad$ Male $\%$ & $57 \%$ & $60 \%$ & $58 \%$ \\
KPS & & & \\
$90-100$ & $58 \%$ & $62 \%$ & $60 \%$ \\
$70-80$ & $42 \%$ & $38 \%$ & $40 \%$ \\
Pancreatic primary location & & \\
Head & $44 \%$ & $42 \%$ & $43 \%$ \\
Body & $31 \%$ & $32 \%$ & $31 \%$ \\
Tail & $24 \%$ & $26 \%$ & $25 \%$ \\
Number of metastatic sites & & \\
I & $8 \%$ & $5 \%$ & $6 \%$ \\
2 & $47 \%$ & $48 \%$ & $47 \%$ \\
$\geq 3$ & $45 \%$ & $47 \%$ & $46 \%$ \\
\hline
\end{tabular}

Abbreviations: KPS, Karnofsky performance score; MPACT, Metastatic Pancreatic Adenocarcinoma Clinical Trial. 
cycles, gemcitabine was given weekly on days 1,8 , and 15 , every 4 weeks. The median overall survival was 8.5 versus 6.7 months (hazard ratio [HR]: $0.72,95 \% \mathrm{CI}$ : $0.62-0.84$, $P=0.001)$, the median progression free survival was 5.5 versus 3.7 months (HR: 0.69 , 95\% CI: $0.58-0.82, P=0.001$ ), and 1 -year survival was $35 \%$ versus $22 \%$, all in favor of the combination of gemcitabine and nab-paclitaxel. ${ }^{40}$

\section{Toxicity}

As shown by the MPACT study, the addition of nab-paclitaxel to gemcitabine in the treatment of patients with advance PC increases survival by 2 months. As noted with any doublet chemotherapy, nab-paclitaxel combined with gemcitabine increased the hematological toxicity profile compared to single agent gemcitabine. Bone marrow suppression was both dose dependent and dose limiting toxicity for the combination of gemcitabine and nab-paclitaxel. Severe neutropenia was noted in $38 \%$ of the combination arm as compared to $27 \%$ in the gemcitabine arm. However, febrile neutropenia was rare in both treatment arms (3\% in doublet and $1 \%$ in gemcitabine). Use of growth factor was higher in the combination arm (26\% versus $15 \%)$ than the standard arm. The main non-hematological toxicity was neuropathy associated with nab-paclitaxel and fatigue, which were more pronounced in the combination arm. Interestingly, most of the peripheral neuropathy was reversible, with grade 1 or less, 30 days after stopping nab-paclitaxel. Other common non-hematologic toxicity symptoms such as alopecia, mucositis, and alterations in taste sensation were compared to the gemcitabine group and are listed in Table 2. Overall, the combination arm was well tolerated and manageable in most advanced PC patients.

\section{Nab-paclitaxel in other cancers}

Taxanes have been recognized as a viable form of therapy for the treatment of breast cancer. Therefore, it was reasonable to evaluate nab-paclitaxel as an alternative to taxol in breast cancer models. ${ }^{41}$ Gradishar et al compared nab-paclitaxel with standard paclitaxel in 454 metastatic breast cancer patients. ${ }^{42}$ The overall response rate was $33 \%$ versus $19 \%$ and the median time-to-progression was 23 versus 16.9 weeks, respectively, favoring nab-paclitaxel. Similarly, Socinski et al reported the result of a Phase III trial comparing nabpaclitaxel with paclitaxel in combination with carboplatin in 1,152 advanced lung cancer patients. ${ }^{43}$ In this trial, nabpaclitaxel was given at $100 \mathrm{mg} / \mathrm{m}^{2}$ on days 1,8 , and 15 of a 3-week cycle in combination with carboplatin area under the curve $=6$ on day 1 every 3 weeks in the experimental arm, while paclitaxel was dosed at $200 \mathrm{mg} / \mathrm{m}^{2}$ on day 1 of a 3 -week
Table 2 Select non-hematologic adverse reactions reported in the MPACT trial

\begin{tabular}{|c|c|c|c|c|}
\hline \multirow[t]{2}{*}{$\begin{array}{l}\text { Adverse } \\
\text { event }\end{array}$} & \multicolumn{2}{|c|}{$\begin{array}{l}\text { Nab-paclitaxel + } \\
\text { gemcitabine } \\
\mathrm{N}=421\end{array}$} & \multicolumn{2}{|c|}{$\begin{array}{l}\text { Gemcitabine } \\
N=402\end{array}$} \\
\hline & $\begin{array}{l}\text { All grades } \\
\text { N (\%) }\end{array}$ & $\begin{array}{l}\text { Grade } 3 \\
\text { or higher } \\
\mathbf{N}(\%)\end{array}$ & $\begin{array}{l}\text { All grades } \\
\text { N (\%) }\end{array}$ & $\begin{array}{l}\text { Grade } 3 \\
\text { or higher } \\
\mathbf{N}(\%)\end{array}$ \\
\hline Fatigue & $248(59 \%)$ & 77 (I8\%) & I 83 (46\%) & 37 (9\%) \\
\hline Pyrexia & $|7|(4 \mid \%)$ & $12(3 \%)$ & $114(28 \%)$ & $4(1 \%)$ \\
\hline Asthenia & 79 (I9\%) & $29(7 \%)$ & 54 (I3\%) & 17 (4\%) \\
\hline Mucositis & $42(10 \%)$ & $6(1 \%)$ & $16(4 \%)$ & $\mathrm{I}(<\mathrm{I} \%)$ \\
\hline Nausea & $228(54 \%)$ & $27(6 \%)$ & 192 (48\%) & $14(3 \%)$ \\
\hline Vomiting & $15 \mid(36 \%)$ & $25(6 \%)$ & $113(28 \%)$ & $15(4 \%)$ \\
\hline Diarrhea & 26 (44\%) & $26(6 \%)$ & 95 (24\%) & $6(1 \%)$ \\
\hline Alopecia & $212(50 \%)$ & $6(1 \%)$ & $21(5 \%)$ & 0 \\
\hline $\begin{array}{l}\text { Peripheral } \\
\text { neuropathy }\end{array}$ & 227 (54\%) & 70 (I7\%) & 51 (13\%) & $3(1 \%)$ \\
\hline Dysgeusia & $68(16 \%)$ & 0 & $33(8 \%)$ & 0 \\
\hline Anorexia & $152(36 \%)$ & $23(5 \%)$ & $104(26 \%)$ & $8(2 \%)$ \\
\hline Arthralgia & 47 (II\%) & $3(1 \%)$ & $13(3 \%)$ & $\mathrm{I}(<\mathrm{l} \%)$ \\
\hline Myalgia & $44(10 \%)$ & $4(1 \%)$ & $15(4 \%)$ & 0 \\
\hline
\end{tabular}

Abbreviation: MPACT, Metastatic Pancreatic Adenocarcinoma Clinical Trial.

cycle at the same dose and schedule of carboplatin. The overall response rate was $33 \%$ versus $25 \%$ and the median overall survival was 12.1 versus 11.2 months, respectively, favoring nab-paclitaxel. Nab-paclitaxel is currently approved in the treatment of both advanced breast and lung cancer patients.

\section{Discussion}

Advanced PC continues to be one of the most aggressive malignancies with limited treatment options. Gemcitabine has been the only treatment for decades. Although the addition of erlotinib statistically increased survival from 5.9 to 6.2 months, it has not been widely adapted into practice due to limited clinical benefit and associated toxicity. The landscape of advanced PC changed when Conroy et al demonstrated that FOLFIRINOX, a (combination of 5-FU, oxaliplatin, and irinotecan) increased the median overall survival in 342 advanced $P C$ patients from 6.4 to 11.1 months when compared with gemcitabine. ${ }^{44}$ However, the regimen was found to increase hematologic and gastrointestinal (GI) toxicity and has been restricted to the very fit, younger patient population with good performance status. A recent survey of practicing American oncologists showed that FOLFIRINOX is used in only about $20 \%-25 \%$ of advanced PC patients due to age and performance status. ${ }^{45,46}$ Therefore, the vast majority of pancreatic patients still receive single agent gemcitabine or other gemcitabine-based regimens. 
It is hard to make any definite conclusions when comparing two different Phase III studies like FOLFIRINOX and MPACT study. However, both modern studies had very similar control groups in terms of overall survival (6.8 months versus 6.7 months) and progression-free survival. In both studies, the demographic profiles for the experimental and control arms were very well balanced. Therefore, if we compare the absolute survival data, FOLFIRINOX had a superior clinical outcome with 11.1 months compared to 8.5 months in the nab-paclitaxel and gemcitabine combination, as well as an improved response rate (32\% versus $23 \%$ ). Therefore, FOLFIRINOX will remain as the standard option in young, fit patients with good performance status in advanced PC.

The MPACT study presented by Von Hoff ${ }^{40}$ demonstrated that nab-paclitaxel and gemcitabine regimen, improved OS of $861 \mathrm{PC}$ patients from 6.7 months to 8.5 months when compared to single agent gemcitabine. The key difference in the eligibility criteria of the FOLFIRINOX and MPACT trials was that the MPACT study allowed elderly patients (age $>75$ years) and that performance status with KPS 70 was allowed in the study. Interestingly, the sub-set analysis of patients who had KPS 70-80 had similar overall survival benefits with KPS $90-100 .{ }^{33}$ The toxicity profile for both gemcitabine and nab-paclitaxel with FOLFIRINOX is similar; however; hematological toxicities and growth factor usage was higher in the FOLFIRINOX arm, while nab-paclitaxel plus gemcitabine demonstrated higher rates of neuropathy. Another practical difference in the two regimens is that the FOLFIRINOX regimen is given every 2 weeks and utilizes the 46-hour 5-FU infusion, while gemcitabine and nab-paclitaxel is given as a weekly infusion.

In conclusion, nab-paclitaxel in combination with gemcitabine has emerged as a new form of therapy for PC and will replaced single agent gemcitabine. It is anticipated that a detailed analysis of the molecular mechanism of action of nab-paclitaxel, especially in the presence of gemcitabine, will allow the better design of therapies against pancreatic adenocarcinoma. Clinical trials using gemcitabine and nabpaclitaxel are already starting to recruit patients to discover its benefit in locally advanced PC and in adjuvant settings. With lower hematological toxicity, this combination should be explored as a backbone in combining novel targeted therapies in the future.

\section{Disclosure}

Dr Choi received honorarium from Celgene. No funding was received for this study. The other authors report no conflicts of interest in this work.

\section{References}

1. Siegel R, Naishadham D, Jemal A. Cancer statistics, 2013. CA Cancer J Clin. 2013;63(1):11-30.

2. Li D, Xie K, Wolff R, Abbruzzese JL. Pancreatic cancer. Lancet. 2004;363(9414):1049-1057.

3. Maitra A, Kern SE, Hruban RH. Molecular pathogenesis of pancreatic cancer. Best Pract Res Clin Gastroenterol. 2006;20(2):211-226.

4. Vincent A, Herman J, Schulick R, Hruban RH, Goggins M. Pancreatic cancer. Lancet. 2011;378(9791):607-620.

5. Tanase CP, Neagu M, Albulescu R, Hinescu ME. Advances in pancreatic cancer detection. Adv Clin Chem. 2010;51:145-180.

6. Abbruzzese JL. Adjuvant therapy for surgically resected pancreatic adenocarcinoma. JAMA. 2008;299(9):1066-1067.

7. Burris HA 3rd, Moore MJ, Andersen J, et al. Improvements in survival and clinical benefit with gemcitabine as first-line therapy for patients with advanced pancreas cancer: a randomized trial. J Clin Oncol. 1997; 15(6):2403-2413.

8. Wang Z, Li Y, Kong D, et al. Acquisition of epithelial-mesenchymal transition phenotype of gemcitabine-resistant pancreatic cancer cells is linked with activation of the notch signaling pathway. Cancer Res. 2009;69(6):2400-2407.

9. Frese KK, Neesse A, Cook N, et al. nab-Paclitaxel potentiates gemcitabine activity by reducing cytidine deaminase levels in a mouse model of pancreatic cancer. Cancer Discov. 2012;2(3):260-269.

10. Hong SP, Wen J, Bang S, Park S, Song SY. CD44-positive cells are responsible for gemcitabine resistance in pancreatic cancer cells. Int $J$ Cancer. 2009;125(10):2323-2331.

11. Moore MJ, Goldstein D, Hamm J, et al. Erlotinib plus gemcitabine compared with gemcitabine alone in patients with advanced pancreatic cancer: a phase III trial of the National Cancer Institute of Canada Clinical Trials Group. J Clin Oncol. 2007;25(15):1960-1966.

12. Belli C, Cereda S, Reni M. Role of taxanes in pancreatic cancer. World $J$ Gastroenterol. 2012;18(33):4457-4465.

13. Rowinsky EK, Calvo E. Novel agents that target tublin and related elements. Semin Oncol. 2006;33(4):421-435.

14. Yared JA, Tkaczuk KH. Update on taxane development: new analogs and new formulations. Drug Des Devel Ther. 2012;6:371-384.

15. Weiss RB, Donehower RC, Wiernik PH, et al. Hypersensitivity reactions from taxol. J Clin Oncol. 1990;8(7):1263-1268.

16. Shepherd GM. Hypersensitivity reactions to chemotherapeutic drugs. Clin Rev Allergy Immunol. 2003;24(3):253-262.

17. Cordes N, Plasswilm L. Cell line and schedule-dependent cytotoxicity of paclitaxel (Taxol): role of the solvent Cremophor EL/ethanol. Anticancer Res. 1998;18(3A):1851-1857.

18. Okada S, Sakata Y, Matsuno S, et al. Phase II study of docetaxel in patients with metastatic pancreatic cancer: a Japanese cooperative study. Cooperative Group of Docetaxel for Pancreatic Cancer in Japan. Br J Cancer. 1999;80(3-4):438-443.

19. Androulakis N, Kourousis C, Dimopoulos MA, et al. Treatment of pancreatic cancer with docetaxel and granulocyte colony-stimulating factor: a multicenter phase II study. J Clin Oncol. 1999;17(6): 1779-1785.

20. Rougier P, Adenis A, Ducreux M, et al. A phase II study: docetaxel as first-line chemotherapy for advanced pancreatic adenocarcinoma. Eur J Cancer. 2000;36(8):1016-1025.

21. Ryan DP, Kulke MH, Fuchs CS, et al. A Phase II study of gemcitabine and docetaxel in patients with metastatic pancreatic carcinoma. Cancer. 2002;94(1):97-103.

22. Stathopoulos GP, Mavroudis D, Tsavaris N, et al. Treatment of pancreatic cancer with a combination of docetaxel, gemcitabine and granulocyte colony-stimulating factor: a phase II study of the Greek Cooperative Group for Pancreatic Cancer. Ann Oncol. 2001;12(1): $101-103$.

23. Sparreboom A, Scripture CD, Trieu V, et al. Comparative preclinical and clinical pharmacokinetics of a cremophor-free, nanoparticle albuminbound paclitaxel (ABI-007) and paclitaxel formulated in Cremophor (Taxol). Clin Cancer Res. 2005;11(11):4136-4143. 
24. Gardner ER, Dahut WL, Scripture CD, et al. Randomized crossover pharmacokinetic study of solvent-based paclitaxel and nab-paclitaxel. Clin Cancer Res. 2008;14(13):4200-4205.

25. Desai N, Trieu V, Yao Z, et al. Increased antitumor activity, intratumor paclitaxel concentrations, and endothelial cell transport of cremophorfree, albumin-bound paclitaxel, ABI-007, compared with cremophorbased paclitaxel. Clin Cancer Res. 2006;12(4):1317-1324.

26. Desai NP, Trieu V, Hwang LY, Wu R, Soon-Shiong P, Gradishar WJ. Improved effectiveness of nanoparticle albumin-bound (nab) paclitaxel versus polysorbate-based docetaxel in multiple xenografts as a function of HER2 and SPARC status. Anticancer Drugs. 2008;19(9): 899-909.

27. Watkins G, Douglas-Jones A, Bryce R, Mansel RE, Jiang WG. Increased levels of SPARC (osteonectin) in human breast cancer tissues and its association with clinical outcomes. Prostaglandins Leukot Essent Fatty Acids. 2005;72(4):267-272.

28. Watkins G, Martin TA, Bryce R, Mansel RE, Jiang WG. Gammalinolenic acid regulates the expression and secretion of SPARC in human cancer cells. Prostaglandins Leukot Essent Fatty Acids. 2005;72(4):273-278.

29. Desai N, Trieu V, Damascelli B, Soon-Shiong P. SPARC expression correlates with tumor response to albumin-bound paclitaxel in head and neck cancer patients. Transl Oncol. 2009;2(2):59-64.

30. Neuzillet C, Tijeras-Raballand A, Cros J, Faivre S, Hammel P, Raymond E. Stromal expression of SPARC in pancreatic adenocarcinoma. Cancer Metastasis Rev. 2013;32(3-4):585-602.

31. Infante JR, Matsubayashi H, Sato N, et al. Peritumoral fibroblast SPARC expression and patient outcome with resectable pancreatic adenocarcinoma. J Clin Oncol. 2007;25(3):319-325.

32. Von Hoff DD, Ramanathan RK, Borad MJ, et al. Gemcitabine plus nab-paclitaxel is an active regimen in patients with advanced pancreatic cancer: a phase I/II trial. J Clin Oncol. 2011;29(34):4548-4554.

33. Neesse A, Frese KK, Chan DS, et al. SPARC independent drug delivery and antitumour effects of nab-paclitaxel in genetically engineered mice. Gut. Epub September 25, 2013.

34. Chu GC, Kimmelman AC, Hezel AF, DePinho RA. Stromal biology of pancreatic cancer. J Cell Biochem. 2007;101(4):887-907.

35. Hidalgo M, Von Hoff DD. Translational therapeutic opportunities in ductal adenocarcinoma of the pancreas. Clin Cancer Res. 2012;18(16): 4249-4256.
36. Mahadevan D, Von Hoff DD. Tumor-stroma interactions in pancreatic ductal adenocarcinoma. Mol Cancer Ther. 2007;6(4):1186-1197.

37. Alvarez R, Musteanu M, Garcia-Garcia E, et al. Stromal disrupting effects of nab-paclitaxel in pancreatic cancer. Br J Cancer. 2013;109(4): 926-933.

38. Von Hoff DD, Bearss D. New drugs for patients with pancreatic cancer. Curr Opin Oncol. 2002;14(6):621-627.

39. Zhang DS, Wang DS, Wang ZQ, et al. Phase I/II study of albuminbound nab-paclitaxel plus gemcitabine administered to Chinese patients with advanced pancreatic cancer. Cancer Chemother Pharmacol. 2013;71(4):1065-1072.

40. Von Hoff DD, Ervin T, Arena FP, et al. Increased survival in pancreatic cancer with nab-paclitaxel plus gemcitabine. $N$ Engl J Med. 2013;369(18):1691-1703.

41. Nyman DW, Campbell KJ, Hersh E, et al. Phase I and pharmacokinetics trial of ABI-007, a novel nanoparticle formulation of paclitaxel in patients with advanced nonhematologic malignancies. J Clin Oncol. 2005;23(31):7785-7793.

42. Gradishar WJ, Tjulandin S, Davidson N, et al. Phase III trial of nanoparticle albumin-bound paclitaxel compared with polyethylated castor oil-based paclitaxel in women with breast cancer. J Clin Oncol. 2005;23(31):7794-7803.

43. Socinski MA, Bondarenko I, Karaseva NA, et al. Weekly nab-paclitaxel in combination with carboplatin versus solvent-based paclitaxel plus carboplatin as first-line therapy in patients with advanced non-small-cell lung cancer: final results of a phase III trial. J Clin Oncol. 2012;30(17): 2055-2062.

44. Conroy T, Desseigne F, Ychou M, et al. FOLFIRINOX versus gemcitabine for metastatic pancreatic cancer. $N$ Engl J Med. 2011; 364(19):1817-1825.

45. Bendell JCBS, Green MR, Willey J, Lemke KE, Marshall J. Immediate impact of the FOLFIRINOX phase III data reported at the 2010 ASCO Annual Meeting on prescribing plans of American oncology physicians for patients with metastatic pancreas cancer (MPC). J Clin Oncol. 2011;29(Suppl 4; Abstract 286).

46. Gill S, Ho MY, Kennecke HF, Renouf DJ, Cheung WY, Lim HJ. Defining eligibility of FOLFIRINOX for the first-line metastatic pancreatic adenocarcinoma (MPC) in the province of the British Columbia: a population based retrospective study. J Clin Oncol. 2012;30(Suppl Abstract e14588).
OncoTargets and Therapy

\section{Publish your work in this journal}

OncoTargets and Therapy is an international, peer-reviewed, open access journal focusing on the pathological basis of all cancers, potential targets for therapy and treatment protocols employed to improve the management of cancer patients. The journal also focuses on the impact of management programs and new therapeutic agents and protocols on

\section{Dovepress}

patient perspectives such as quality of life, adherence and satisfaction The manuscript management system is completely online and includes a very quick and fair peer-review system, which is all easy to use. Visit http://www.dovepress.com/testimonials.php to read real quotes from published authors. 